\title{
GOVERNANÇA PÚBLICA: INVESTIMENTO EM EDUCAÇÃO E SUA RELAÇÃO COM O DESEMPENHO DOS ESTUDANTES NOS MUNICÍPIOS DA SERRA GAÚCHA
}

http://dx.doi.org/10.5902/2318133842486

\author{
Alex Eckert ${ }^{1}$ \\ Deise Cioato ${ }^{2}$ \\ Marlei Salete $\mathrm{Mecca}^{3}$
}

\begin{abstract}
Resumo
Os gastos relacionados com a educação estão previstos na Constituição Federal, na qual são estipulados limites mínimos a serem aplicados. Neste sentido, o presente estudo teve como objetivo analisar os gastos relacionados com educação básica nos municípios da Serra Gaúcha no período de 2014 a 2018, tomando por base os limites estipulados na Constituição Federal, e verificar se tais gastos refletem no desempenho dos estudantes. Do ponto de vista metodológico realizou-se uma pesquisa documental, descritiva e qualitativa. Os resultados evidenciaram que todos os municípios analisados cumprem com a obrigatoriedade de aplicação em manutenção e desenvolvimento do ensino, e que os seus gastos nesta rubrica não têm relação direta com o desempenho dos estudantes.
\end{abstract}

Palavras-chaves: gastos públicos; municípios; investimento em educação; manutenção e desenvolvimento do ensino.

\section{PUBLIC GOVERNANCE: INVESTMENT IN EDUCATION AND ITS RELATIONSHIP WITH THE PERFORMANCE OF STUDENTS IN THE BRAZILIAN REGION OF SERRA GAÚCHA}

\begin{abstract}
Expenses related to education are provided for in the Federal Constitution of Brazil, in which minimum limits are set to be applied. Thus, the present study aimed to make an analysis of expenses related to basic education in the municipalities of Serra Gaúcha in the period from 2014 to 2018, based on the limits stipulated in the Federal Constitution, and to verify whether such expenses reflect on the performance of students. To achieve the objective, a documentary, descriptive and qualitative research was carried out. The results found showed that all municipalities analyzed comply with the mandatory application of resources in education, and that their spending has no direct relationship with the performance of students.

Key-words: public spending; counties; investment in education; maintenance and development of education.
\end{abstract}

\footnotetext{
1 Universidade de Caxias do Sul, Brasil. E-mail: alex.eckert@bol.com.br.

2 Universidade de Caxias do Sul, Brasil. E-mail: dcioato@ucs.br.

3 Universidade de Caxias do Sul, Brasil. E-mail: msmecca@ucs.br.

Regae: Rev. Gest. Aval. Educ.

Pub. contínua 2020

p. $1-23$
} 


\section{Introdução}

educação tem um papel importante na vida de todos, pois é por meio dela
que se adquire conhecimento, aprende-se a viver em sociedade, a
compartilhar os aprendizados. Cabe a cada família incentivar as crianças e jovens na sua formação, garantindo uma preparação para um futuro promissor, com melhor qualidade de vida.

É garantido por lei o direito a educação de qualidade, independentemente de sua origem ou idade. No art. 6 ㅇ da Constituição Federal consta que "são direitos sociais, a educação, a saúde, a alimentação, o trabalho, a moradia, o lazer, a segurança, a previdência social, a proteção, à maternidade, à infância, e a assistência aos desamparados".

Ainda na Lei das Diretrizes e Bases da Educação Nacional, no art. 4ํㅡㄹ consta que "o dever do Estado com educação escolar pública será efetivado mediante a garantia de Educação Básica obrigatória e gratuita dos 4 aos 17 anos de idade, organizadas da seguinte forma, pré-escola, ensino fundamental e ensino médio".

Conforme dados disponibilizados pelo Fundo Nacional de Desenvolvimento da Educação - FNDE -, os recursos vinculados à educação, tanto nos municípios, quanto nos Estados, são oriundos do Fundo de Manutenção e Desenvolvimento da Educação Básica e de Valorização dos Profissionais da Educação - Fundeb. Sua distribuição é automática e, feita de acordo com o Censo Escolar, tem como base o número de alunos matriculados nas escolas. Os municípios utilizam-se destes recursos na educação infantil e ensino fundamental, enquanto que o Estado no ensino fundamental e médio.

É importante analisar se os gastos com a educação básica são utilizados e distribuídos de forma correta, partindo-se do pressuposto da lei complementar $\mathrm{n}$. 101/2000, Lei de Responsabilidade Fiscal - LRF -, instituída com o objetivo de manter o equilíbrio das contas públicas. Nela pressupõe-se que a gestão fiscal seja elaborada de forma planejada e transparente, prevenindo-se os riscos e corrigindo-se os desvios nos órgãos públicos.

Além disso, a governança pública, norteada pelos princípios básicos da transparência, equidade, cumprimento das leis, prestação de contas e conduta ética, está cada vez mais presente no cotidiano das entidades, justificada pelo argumento de que necessita existir um controle sobre a gestão e sobre os instrumentos definidores de responsabilidades e poder, bem como o acompanhamento e o incentivo na execução das políticas e objetivos pré-determinados (Matias Pereira, 2010).

Diante disso, o objetivo do presente estudo foi analisar os gastos relacionados com educação básica nos municípios da Serra Gaúcha, no período de 2014 a 2018, tomando por base os limites estipulados na Constituição Federal, e verificar se tais gastos refletem no desempenho dos estudantes. A partir dos resultados foi possível saber quais os gastos com a Educação Básica em cada um dos municípios, evidenciar se os mesmos estão sendo aplicados de forma correta, conforme previsto na legislação.

A ambiência da pesquisa foram os municípios localizados na Serra Gaúcha. Conforme o Instituto Brasileiro de Geografia e Estatística (IBGE, 2019), o Estado do Rio Grande do Sul é composto por 497 municípios e divide-se em 28 regiões, as quais são 
regidas por conselhos, que colaboram para o desenvolvimento regional. A região da Serra Gaúcha é vinculada ao Conselho Regional de Desenvolvimento da Serra - Corede Serra, do qual fazem parte 32 municípios.

\section{Administração pública}

A Administração Pública executa e realiza serviços os quais buscam a satisfação das necessidades da população. A administração é composta por um conjunto de órgãos, sendo eles de entidades da administração direta e da administração indireta, os quais são instituídos por lei e visam a conquistar os objetivos do governo (Dias, 2017).

A administração centralizada, ou direta, forma-se pelos órgãos das três esferas de governo, sendo eles, Federal, Estadual e Municipal. Estes se distribuem em três poderes, Legislativo, Executivo e Judiciário, os quais são regidos pela Constituição Federal, Constituição Estadual e pelas leis orgânicas dos municípios (Lima; Muniz, 2016). Andrade (2017) posiciona-se em relação à administração direta como sendo o conjunto de atividades e serviços que são integrados na estrutura administrativa da presidência da República, do governo do Estado ou da Prefeitura Municipal. Desta maneira pode-se citar que na administração direta estão presentes órgãos os quais se responsabilizam pela realização das necessidades básicas da população, como saúde, educação, lazer, assistência social, transporte, segurança pública, entre outras (Dias, 2017).

Já a administração descentralizada, ou indireta, foi criada com o objetivo de fornecer maior eficiência à gestão governamental (Castro, 2018). Lima e Muniz (2016) destacam que a administração indireta forma-se pelo conjunto das entidades às quais prestam serviços públicos ligados aos órgãos de administração direta, em especial aos ministérios ou secretarias estaduais e municipais.

\section{Contabilidade pública}

Segundo Castro (2018) a contabilidade direcionada ao setor público busca evidenciar os efeitos das ações de governo, bem como o reflexo nas finanças públicas e no patrimônio, voltadas a aceitação da sociedade. Para Andrade (2017), a contabilidade pública, ou governamental, tem como objeto de estudo o patrimônio público, analisando os atos e fatos ocorridos, bem como os resultados apresentados, fornecendo informações aos usuários, nos aspectos de natureza física, financeira, orçamentária e econômica, levando-se em consideração a evidência de todas as mutações ocorridas nos processos de gestão, a prestação de contas e o suporte para a tomada de decisão e o controle social.

Na contabilidade pública permite-se somente colocar em prática o que está previsto em lei, ou seja, deve-se efetuar previsão legal para se efetivar qualquer ação governamental. A contabilidade pública não busca o lucro financeiro ou econômico, bem como utiliza-se do patrimônio em razão dos objetivos sociais pretendidos, prestando serviços nos quais se gerará benefícios futuros para a população (Andrade, 2017).

Lima (2018) destaca que os usuários da contabilidade pública classificam-se em externos e internos, sendo que os externos compreendem o grupo dos cidadãos, o grupo do corpo legislativo e o grupo de investidores e credores, enquanto que os usuários internos compreendem os órgãos de gestão das entidades. 
Um dos objetivos da contabilidade pública é a elaboração do orçamento público, pelo qual o governo estipula onde serão utilizados os valores obtidos como os tributos, estima as receitas a serem arrecadadas, bem como as despesas fixas a serem efetuadas durante o ano em vigência. Esta ferramenta verifica a situação atual do governo, para posteriormente efetivar as futuras alterações necessárias para atingir as metas desejadas (Portal da Transparência, 2019). Associado a isto Lima (2018) destaca que o orçamento evidencia o caminho a ser seguido pela administração pública, da liberdade para arrecadar e gastar dentro dos limites que se contém no próprio orçamento.

No art. 165 da Constituição Federal são estabelecidos os processos de planejamento do orçamento, sendo que estes dispõem de metas e objetivos para melhor direcionar-se às receitas e despesas dos governos, bem como a execução dos orçamentos, sejam de curto ou longo prazo, de esfera federal, estadual ou mesmo municipal. Conforme Kohama (2016) o orçamento público compõe-se de três instrumentos básicos para sua elaboração sendo eles, o plano plurianual - PPA -, a lei de diretrizes orçamentárias - LDO - e a lei orçamentária anual - LOA.

\section{Receitas e despesas orçamentárias}

Conforme o Manual da contabilidade aplicada ao setor público (MCASP, 2018) entende-se como sendo receita orçamentária a entrada de recursos financeiros nos cofres do Estado, sendo que estes recursos provêm do recebimento de impostos, taxas e contribuições. Lima (2018) sustenta que as receitas orçamentárias representam as disponibilidades dos recursos financeiros que ingressam no ente federado durante o exercício, aumentando assim o saldo financeiro. Estes recursos se destinam a programas e ações para atender as demandas da sociedade (Lima, 2018).

Já a despesa orçamentária pode ser compreendida como toda saída de recurso ou mesmo pagamentos de qualquer título, os quais utilizam-se destes para saldar gastos previamente fixados na lei do orçamento, destinados à execução dos serviços públicos, pagamentos de dívidas, devolução de importâncias recebidas a títulos de caução, depósitos e consignações (Andrade, 2017).

De acordo com o MCASP (2018) classifica-se como despesa orçamentária o somatório dos dispêndios dos recursos, estes vinculados aos cofres do Estado. As entidades públicas utilizam-se destes recursos para manutenção do bem público, visando ao bom funcionamento dos órgãos e serviços, os quais são disponibilizados a sociedade em geral. No grupo das despesas existem aquelas relacionadas com a educação, ou seja, as que nos municípios se fazem necessárias para o desenvolvimento da administração do ano letivo nas áreas da educação básica junto as escolas.

Conforme a LDB, art. 70, as despesas que fazem parte do ensino destinam-se à aquisição ou mesmo aperfeiçoamento dos objetivos básicos das instituições de ensino, tais como remuneração e aperfeiçoamento do pessoal docente e demais profissionais da educação; aquisição, manutenção, construção e conservação de instalações e equipamentos necessários ao ensino; uso e manutenção de bens e serviços vinculados ao ensino; estudos e pesquisas visando o aprimoramento da qualidade e a expansão do ensino; realização de atividade-meio necessárias ao funcionamento dos sistemas de 
ensino; concessão de bolsas de estudo a alunos de escolas públicas e privadas; amortização e custeio de operações de crédito voltadas à educação; aquisição de material didático-escolar; manutenção de programas de transporte escolar.

Para um melhor controle das receitas e despesas orçamentárias, foi criada no ano de 2000 a Lei de Responsabilidade Fiscal, com o objetivo de estabelecer normas de finanças públicas, voltadas a responsabilidade na gestão fiscal, validadas a todos os órgãos públicos nas esferas federal, estadual e municipal (Dias, 2017). Abraham (2017) afirma que, com a implantação da LRF, o caos e a irresponsabilidade fiscal que assolavam o país tiveram redução significante. Segundo o autor, possibilitou-se um maior controle sobre as despesas sem procedência e o desequilíbrio das receitas e despesas públicas.

\section{Educação e a Constituição Federal de 1988}

A educação destaca-se como sendo base para todos, indiferentes de nacionalidade ou mesmo idade. É por ela que se adquire-se conhecimento e abre-se os horizontes para as diferentes etapas da vida. Conforme a Constituição Federal de 1988, art. 205, no Brasil a educação é direito de todos, assegurada em lei, e cabe ao Estado e às famílias, a garantia de que as crianças tenham acesso à escola, nas etapas da educação infantil, ensino fundamental e ensino médio, buscando assim o aprendizado.

A educação básica é oferecida pelas entidades escolares, de forma gratuita, para crianças e adolescentes, com idades entre quatro e dezessete anos. Para que não haja diferenças e todos sejam tratados com igualdade e respeito, o ensino é ministrado com base em alguns princípios definidos no art. 206 da CF: igualdade de condições para 0 acesso e permanência na escola; liberdade de aprender, ensinar, pesquisar e divulgar o pensamento, a arte e o saber; pluralismo de ideias e de concepções pedagógicas, e coexistência de instituições públicas e privadas de ensino; gratuidade do ensino público em estabelecimentos oficiais.

Ficou estabelecido que cabe aos municípios a educação infantil, e de forma conjunta com o Estado o ensino fundamental. Já o Distrito Federal atuará no ensino fundamental e médio. A União, os Estados o Distrito Federal e os Municípios definirão de forma conjunta os sistemas de ensino, para assegurar a universalidade do ensino obrigatório. No art. 212 da Constituição Federal estipulam-se os percentuais aplicados anualmente na manutenção e desenvolvimento do ensino - MDE -, sendo estes percentuais nunca inferiores a $18 \%$ por parte da União, e $25 \%$ no mínimo da receita resultante dos impostos nos Estados, o Distrito Federal e municípios.

\section{Aspectos metodológicos}

A presente pesquisa enquadra-se como sendo uma pesquisa documental que, para Fachin (2017), engloba toda informação reunida na forma escrita ou mesma oral, as quais devem se seguir métodos e técnicas específicas. Já quanto aos objetivos esta pesquisa foi constituída de forma descritiva, sendo que para Gil (2018) estas pesquisas fazem parte da descrição das características de determinada população ou fenômeno, mas também se utiliza quando há a necessidade de identificar possíveis relações entre variáveis. 
No que se refere à forma de abordagem esta pesquisa enquadrou-se como sendo de abordagem qualitativa. De acordo com Matias-Pereira (2019) numa pesquisa qualitativa os dados não podem ser quantificáveis, estes precisam ser analisados de forma indutiva, tendo a interpretação e a atribuição dos fenômenos de forma básica. Para Fachin (2017) a abordagem qualitativa necessita ser categorizada, definida e analisada.

Iniciou-se com uma revisão bibliográfica sobre o tema em questão. A pesquisa baseou-se em livros, artigos e periódicos bem como, outras fontes disponíveis. Posteriormente fez-se uma breve introdução dos municípios os quais fazem parte do Corede Serra, embasados em dados coletados oficialmente. Além disso foi feita a coleta de dados em sites oficiais de 2014 a 2018, referente aos gastos com a educação básica. Os mesmos foram transcritos em planilhas eletrônicas.

Paralelo a isso foram identificadas as receitas que, embasadas na lei, distribuem-se em percentuais, os quais são destinados à educação básica, bem como uma análise das despesas destinadas ao setor da educação. De forma semelhante foi realizada a análise das porcentagens da receita para evidenciar se as mesmas estão sendo investidas de forma correta e embasadas nos percentuais descritos e condizentes com as despesas realizadas. Por fim foi feita uma análise dos resultados encontrados, para posterior alinhamento com o objetivo e conformidade com a pesquisa realizada.

\section{Apresentação dos dados e análise dos resultados \\ Dados demográficos}

Conforme o portal do IBGE (2019), na região da Serra Gaúcha nela encontram-se municípios com atividades econômicas relevantes. Pode-se citar entre estes setores 0 polo metalomecânico e o moveleiro. Há predominância em vários municípios do cultivo da videira e a produção do vinho, além do turismo. Os 32 municípios desta região se vinculam ao Conselho Regional de Desenvolvimento da Serra Gaúcha - Corede Serra.

Tabela 1 -

Municípios da Serra Gaúcha.

\begin{tabular}{|c|c|c|c|c|c|c|c|}
\hline \multirow[b]{2}{*}{ Cód. } & \multirow{2}{*}{$\begin{array}{l}\text { Municípios } \\
\text { (FEE) }\end{array}$} & \multicolumn{5}{|c|}{ Habitantes (estimativa) } & \multirow{2}{*}{$\begin{array}{c}\text { Área }\left(\mathrm{KM}^{2}\right) \\
(\mathrm{IBGE})\end{array}$} \\
\hline & & $\begin{array}{l}2014 \\
\text { (FEE) }\end{array}$ & $\begin{array}{l}2015 \\
\text { (FEE) }\end{array}$ & $\begin{array}{l}2016 \\
\text { (FEE) }\end{array}$ & $\begin{array}{l}2017 \\
\text { (FEE) }\end{array}$ & $\begin{array}{c}2018 \\
(\text { IBGE) }\end{array}$ & \\
\hline M1 & Antônio Prado & 12.781 & 12.899 & 13.013 & 12.969 & 13.055 & 348,15 \\
\hline M2 & Bento Gonçalves & 115.606 & 118.255 & 119.723 & 120.961 & 119.049 & 273,96 \\
\hline M3 & Boa Vista do Sul & 2.987 & 2.993 & 3.015 & 2.956 & 2.788 & 92,93 \\
\hline M4 & Carlos Barbosa & 26.858 & 27.838 & 28.793 & 29.182 & 29.409 & 229,99 \\
\hline M5 & Caxias do Sul & 464.027 & 468.234 & 469.604 & 468.518 & 504.069 & $1.652,70$ \\
\hline M6 & Coronel Pilar & 1.673 & 1.667 & 1.691 & 1.712 & 1641 & 105,45 \\
\hline M7 & Cotiporã & 3.768 & 3.796 & 3.828 & 3.906 & 3868 & 172,38 \\
\hline M8 & Fagundes Varela & 2.668 & 2.659 & 2.694 & 2.716 & 2721 & 134,30 \\
\hline M9 & Farroupilha & 67.892 & 68.457 & 69.034 & 69.598 & 71.570 & 361,73 \\
\hline M10 & Flores da Cunha & 29.021 & 29.352 & 29.825 & 30.095 & 30.430 & 273,64 \\
\hline M11 & Garibaldi & 32.678 & 33.421 & 34.141 & 34.648 & 34.684 & 168,14 \\
\hline M12 & Guabiju & 1.556 & 1.589 & 1.615 & 1.629 & 1.516 & 146,53 \\
\hline M13 & Guaporé & 24.792 & 25.008 & 25.403 & 25.676 & 25.475 & 297,55 \\
\hline \multicolumn{2}{|c|}{ Regae: Rev. Gest. Aval. Educ. } & a Maria & v. 9 & n. 18 & \multicolumn{2}{|c|}{ Pub. contínua 2020} & p. 1-23 \\
\hline
\end{tabular}




\begin{tabular}{|l|l|r|r|r|r|r|r|} 
M14 & Montauri & 1.541 & 1.567 & 1.575 & 1.590 & 1.466 & 82,08 \\
\hline M15 & Monte Belo do Sul & 2.713 & 2.753 & 2.724 & 2.709 & 2.564 & 69,60 \\
\hline M16 & Nova Araçá & 4.435 & 4.626 & 4.827 & 4.972 & 4.690 & 74,70 \\
\hline M17 & Nova Bassano & 8.947 & 9.000 & 9.002 & 9.023 & 9.824 & 211,61 \\
\hline M18 & Nova Pádua & 2.480 & 2.540 & 2.594 & 2.633 & 2.548 & 102,73 \\
\hline M19 & Nova Prata & 24.465 & 24.838 & 25.170 & 25.371 & 26.849 & 258,91 \\
\hline M20 & Nova Roma do Sul & 3.593 & 3.587 & 3.639 & 3.657 & 3.293 & 149,14 \\
\hline M21 & Paraí & 7.086 & 7.132 & 7.363 & 7.478 & 7.585 & 122,43 \\
\hline M22 & Pinto Bandeira & 2.909 & 2.978 & 3.014 & 3.043 & 2.968 & 104,86 \\
\hline M23 & Protásio Alves & 2.087 & 2.125 & 2.124 & 2.166 & 1.957 & 173,03 \\
\hline M24 & Santa Tereza & 1.750 & 1.755 & 1.756 & 1.761 & 1.734 & 73,98 \\
\hline M25 & São Jorge & 2.664 & 2.683 & 2.707 & 2.674 & 2.757 & 117,38 \\
\hline M26 & São Marcos & 21.047 & 21.334 & 21.407 & 21.358 & 21.449 & 256,36 \\
\hline M27 & São Valentim do Sul & 2.275 & 2.384 & 2.417 & 2.386 & 2.239 & 91,90 \\
\hline M28 & Serafina Corrêa & 15.208 & 15.641 & 16.064 & 16.370 & 17.198 & 163,28 \\
\hline M29 & União da Serra & 1.433 & 1.401 & 1.400 & 1.395 & 1.192 & 130,99 \\
\hline M30 & Veranópolis & 24.148 & 24.016 & 24.129 & 24.141 & 25.936 & 290,10 \\
\hline M31 & Vila Flores & 3.376 & 3.397 & 3.426 & 3.527 & 3.374 & 107,50 \\
\hline M32 & Vista Alegre do Prata & 1.582 & 1.630 & 1.677 & 1.645 & 1.565 & 119,33 \\
\hline & Total & 920.046 & 931.555 & 939.394 & 942.465 & 981.463 & $6.957,31$ \\
\hline
\end{tabular}

Fonte: elaborada pelos autores com base em FEE (2019) e IBGE (2019).

Pela tabela 1 pode-se observar que o município que dispõe da maior população é Caxias do Sul com, aproximadamente, 504.069 habitantes, o que representa um percentual superior a $51 \%$ em relação ao total de habitantes nos respectivos anos analisados, seguido de Bento Gonçalves, com percentual de 12,13\%, e Farroupilha com $7,29 \%$ do total de habitantes. Já os municípios de União da Serra, Montauri, Guabiju, Vista Alegre do Prata, Coronel Pilar e Santa Tereza possuem em sua população números inferiores a 2.000 habitantes que, juntos, representam um percentual inferior a $1 \%$ do total da população.

Na seqüência apresenta-se os habitantes em idade escolar, tomando por base a educação básica. Leva-se em consideração que a faixa etária do 0 aos 5 anos engloba a população a qual faz parte da modalidade de educação infantil, ou seja, pertencentes à creche e a pré-escola, em idades entre 6 e 14 anos o ensino fundamental e dos 15 aos 17 anos o ensino médio. Ressalta-se a importância de que as idades entre 0 e 4 anos incompletos não possuem obrigatoriedade de permanência na educação infantil dos respectivos municípios: a obrigatoriedade escolar encontra-se a partir dos 4 anos completos, sempre obedecendo-se ao calendário escolar de cada município. 
Tabela 2 -

Quantidade de habitantes em idade escolar.

\begin{tabular}{|c|c|c|c|c|c|c|}
\hline \multirow[b]{2}{*}{ Cód. } & \multirow[b]{2}{*}{ Municípios } & \multicolumn{5}{|c|}{ Habitantes em idade escolar (aproximadamente) } \\
\hline & & $\begin{array}{l}2014 \\
\text { (FEE) } \\
\end{array}$ & $\begin{array}{l}2015 \\
\text { (FEE) } \\
\end{array}$ & \begin{tabular}{l|}
2016 \\
(FEE) \\
\end{tabular} & $\begin{array}{l}2017 \\
\text { (FEE) }\end{array}$ & $\begin{array}{l}2018 \\
\text { (IBGE) }\end{array}$ \\
\hline M1 & Antônio Prado & 2.971 & 2.938 & 2.876 & 2.779 & 3.313 \\
\hline M2 & Bento Gonçalves & 28.632 & 29.300 & 29.425 & 29.320 & 27.047 \\
\hline M3 & Boa Vista do Sul & 555 & 540 & 535 & 497 & 558 \\
\hline M4 & Carlos Barbosa & 6.235 & 6.516 & 6.810 & 6.804 & 6.219 \\
\hline M5 & Caxias do Sul & 125.604 & 125.607 & 124.098 & 121.562 & 121.968 \\
\hline M6 & Coronel Pilar & 296 & 288 & 285 & 287 & 364 \\
\hline M7 & Cotiporã & 654 & 639 & 628 & 641 & 854 \\
\hline M8 & Fagundes Varela & 551 & 528 & 530 & 521 & 582 \\
\hline M9 & Farroupilha & 17.851 & 17.726 & 17.624 & 17.484 & 17.486 \\
\hline M10 & Flores da Cunha & 7.285 & 7.283 & 7.341 & 7.335 & 7.057 \\
\hline M11 & Garibaldi & 7.437 & 7.662 & 7.795 & 7.885 & 7.467 \\
\hline M12 & Guabiju & 300 & 298 & 301 & 290 & 360 \\
\hline M13 & Guaporé & 6.265 & 6.209 & 6.261 & 6.240 & 6.038 \\
\hline M14 & Montauri & 282 & 284 & 272 & 272 & 324 \\
\hline M15 & Monte Belo do Sul & 455 & 455 & 431 & 405 & 530 \\
\hline M16 & Nova Araçá & 1.033 & 1.096 & 1.156 & 1.199 & 1.006 \\
\hline M17 & Nova Bassano & 2.039 & 2.019 & 1.969 & 1.947 & 2.235 \\
\hline M18 & Nova Pádua & 475 & 477 & 485 & 468 & 548 \\
\hline M19 & Nova Prata & 6.174 & 6.244 & 6.327 & 6.336 & 6.001 \\
\hline M20 & Nova Roma do Sul & 815 & 787 & 789 & 757 & 837 \\
\hline M21 & Paraí & 1.656 & 1.639 & 1.706 & 1.713 & 1.757 \\
\hline M22 & Pinto Bandeira & 721 & 739 & 742 & 738 & N.D. \\
\hline M23 & Protásio Alves & 431 & 432 & 423 & 435 & 459 \\
\hline M24 & Santa Tereza & 312 & 290 & 285 & 276 & 337 \\
\hline M25 & São Jorge & 564 & 546 & 534 & 509 & 692 \\
\hline M26 & São Marcos & 5.289 & 5.263 & 5.163 & 5.033 & 5.500 \\
\hline M27 & São Valentim do Sul & 421 & 450 & 456 & 420 & 459 \\
\hline M28 & Serafina Corrêa & 3.979 & 4.102 & 4.205 & 4235 & 3.924 \\
\hline M29 & União da Serra & 243 & 217 & 203 & 191 & 304 \\
\hline M30 & Veranópolis & 5.533 & 5.365 & 5.312 & 5.210 & 5.473 \\
\hline M31 & Vila Flores & 699 & 679 & 675 & 703 & 748 \\
\hline M32 & Vista Alegre do Prata & 303 & 319 & 332 & 300 & 348 \\
\hline & Total & 236.060 & 236.937 & 235.974 & 232.792 & 230.795 \\
\hline
\end{tabular}

Fonte: elaborada pelos autores com base em FEE (2019) e IBGE (2019).

Pela tabela 2 é possível observar que a maior concentração de alunos em idade escolar encontra-se no município de Caxias do Sul, com 121.968, seguido de Bento Gonçalves com 27.047 pessoas em idade escolar, e Farroupilha, com 17.486 habitantes, 
nas suas totalidades no ano de 2018. Em contrapartida os municípios de União da Serra, Montauri e Santa Tereza encontram-se entre os municípios com a menor população em idade escolar: números inferiores a 340 habitantes.

Associando-se aos dados citados anteriormente, demonstra-se na tabela 3 o número de matrículas efetivadas nas redes de ensino referentes à Educação Básica dos municípios analisados neste estudo.

Tabela 3 -

Matrículas da educação básica nos municípios da Serra Gaúcha.

\begin{tabular}{|c|c|c|c|c|c|c|}
\hline \multirow[b]{2}{*}{ Cód. } & \multirow[b]{2}{*}{ Municípios } & \multicolumn{5}{|c|}{ Matrículas na educação básica } \\
\hline & & $\begin{array}{l}2014 \\
\text { (Inep) }\end{array}$ & $\begin{array}{l}2015 \\
\text { (Inep) }\end{array}$ & $\begin{array}{l}2016 \\
\text { (Inep) }\end{array}$ & $\begin{array}{l}2017 \\
\text { (Inep) } \\
\end{array}$ & $\begin{array}{l}2018 \\
\text { (Inep) }\end{array}$ \\
\hline M1 & Antônio Prado & 2.522 & 2.446 & 2.398 & 2.568 & 2.485 \\
\hline M2 & Bento Gonçalves & 22.343 & 22.020 & 22.048 & 22.056 & 23.035 \\
\hline M3 & Boa Vista do Sul & 338 & 336 & 337 & 343 & 327 \\
\hline M4 & Carlos Barbosa & 4.729 & 4.743 & 4.936 & 4.989 & 5.149 \\
\hline M5 & Caxias do Sul & 97.721 & 98.046 & 98.032 & 96.712 & 96.180 \\
\hline M6 & Coronel Pilar & 207 & 195 & 201 & 200 & 190 \\
\hline M7 & Cotiporã & 500 & 470 & 469 & 460 & 436 \\
\hline M8 & Fagundes Varela & 445 & 415 & 409 & 421 & 391 \\
\hline M9 & Farroupilha & 14.500 & 14.453 & 14.139 & 14.245 & 14.219 \\
\hline M10 & Flores da Cunha & 5.260 & 5.178 & 5.362 & 5.309 & 5.405 \\
\hline M11 & Garibaldi & 5.688 & 5.777 & 5.675 & 5.731 & 5.716 \\
\hline M12 & Guabiju & 202 & 199 & 213 & 221 & 215 \\
\hline M13 & Guaporé & 5.196 & 5.215 & 5.299 & 5.345 & 5.333 \\
\hline M14 & Montauri & 229 & 208 & 212 & 219 & 228 \\
\hline M15 & Monte Belo do Sul & 380 & 348 & 341 & 346 & 334 \\
\hline M16 & Nova Araçá & 907 & 951 & 967 & 1.018 & 1.039 \\
\hline M17 & Nova Bassano & 1.743 & 1.678 & 1.648 & 1.566 & 1.492 \\
\hline M18 & Nova Pádua & 354 & 360 & 350 & 333 & 357 \\
\hline M19 & Nova Prata & 5.193 & 5.379 & 5.501 & 5.404 & 5.577 \\
\hline M20 & Nova Roma do Sul & 552 & 550 & 537 & 501 & 512 \\
\hline M21 & Paraí & 1.289 & 1.304 & 1.283 & 1.285 & 1.255 \\
\hline M22 & Pinto Bandeira & 351 & 345 & 402 & 365 & 398 \\
\hline M23 & Protásio Alves & 337 & 310 & 305 & 307 & 307 \\
\hline M24 & Santa Tereza & 218 & 226 & 204 & 198 & 198 \\
\hline M25 & São Jorge & 444 & 428 & 415 & 391 & 399 \\
\hline M26 & São Marcos & 4.128 & 4.015 & 4.053 & 3.912 & 3.942 \\
\hline M27 & São Valentim do Sul & 301 & 300 & 317 & 316 & 338 \\
\hline M28 & Serafina Corrêa & 3.151 & 3.161 & 3.277 & 3.276 & 3.295 \\
\hline M29 & União da Serra & 216 & 200 & 189 & 177 & 176 \\
\hline
\end{tabular}




\begin{tabular}{|l|l|r|r|r|r|r|} 
M30 & Veranópolis & 4.746 & 4.715 & 4.862 & 4.807 & 4.613 \\
\hline M31 & Vila Flores & 491 & 517 & 516 & 511 & 501 \\
\hline M32 & Vista Alegre do Prata & 229 & 247 & 239 & 245 & 263 \\
\hline \multicolumn{2}{|}{ Total } & 184.910 & 184.735 & 185.136 & 183.777 & 184.305 \\
\hline
\end{tabular}

Fonte: elaborada pelos autores com base em Inep (2019).

Assim, pela tabela 3 é possível identificar as matrículas efetivadas em cada um dos municípios da região da Serra Gaúcha referentes aos anos de 2014 a 2018. Cada ano é composto pelas vagas relacionadas à educação básica, compreendendo-se as etapas da educação infantil, esta por sua vez, engloba a creche e a pré-escola, com faixa etária entre 0 e 5 anos. Evidencia-se que as idades entre 0 e 4 anos incompletos não possuem obrigatoriedade de permanência nas escolas.

\section{Receitas líquidas de impostos e transferências}

Para melhor compreensão do que foi proposto no objetivo deste trabalho, apresentase a tabela com as Receitas Líquidas de impostos e transferências dos 32 municípios da Serra Gaúcha, no período de 2014 a 2018. As receitas nele demonstradas são constituídas pelos impostos e transferências, de eventuais juros e multas incidentes sobre os mesmos.

Tabela 4 -

Receitas Líquidas de impostos e transferências (ajustadas - R\$).

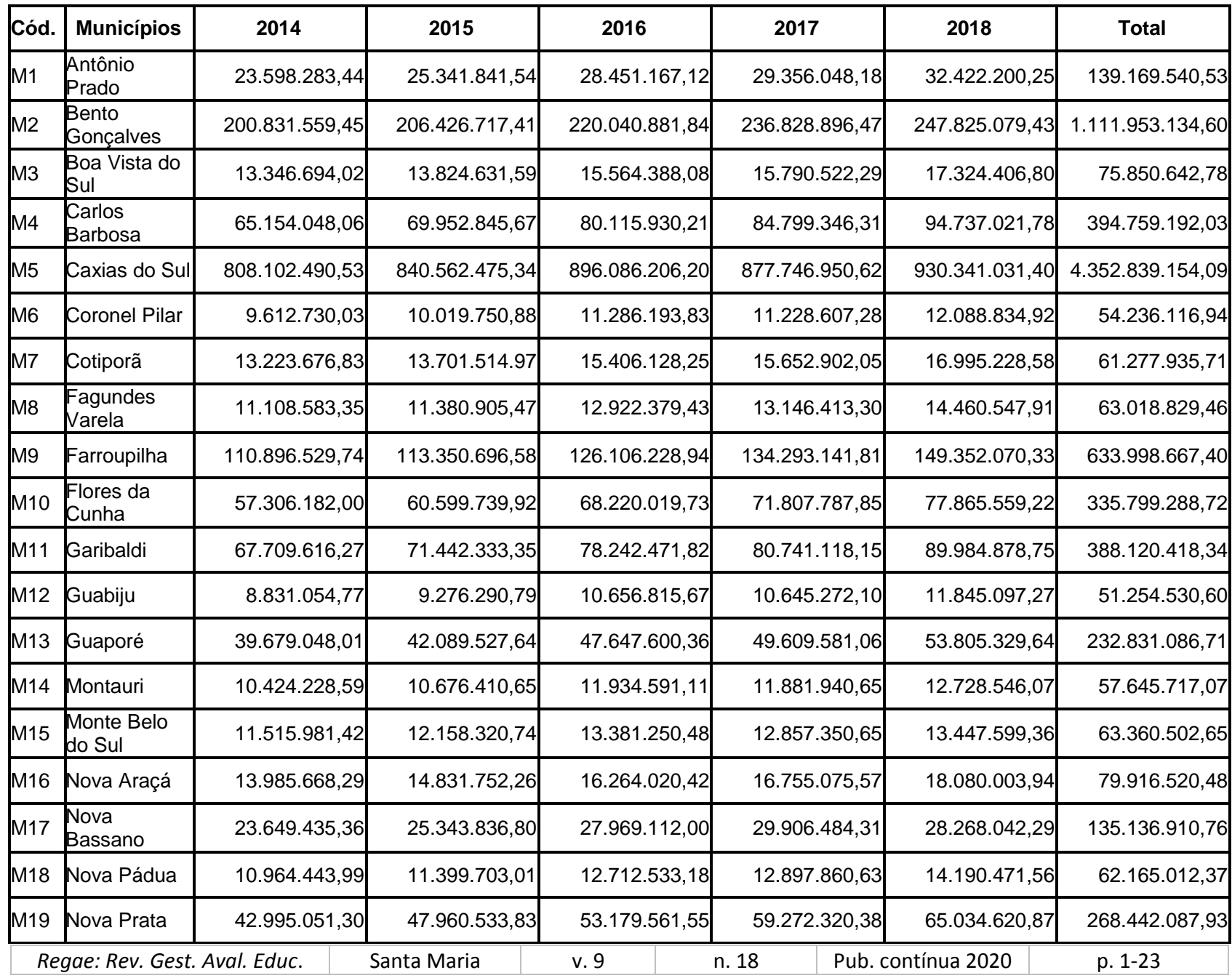




\begin{tabular}{|l|l|r|r|r|r|r|r|}
\hline M20 & $\begin{array}{l}\text { Nova Roma } \\
\text { do Sul }\end{array}$ & $14.670 .230,61$ & $15.374 .066,39$ & $17.245 .677,12$ & $17.424 .069,36$ & $18.833 .525,25$ & $83.547 .568,73$ \\
\hline M21 & Paraí & $17.077 .504,28$ & $17.681 .655,33$ & $19.406 .652,46$ & $20.323 .955,01$ & $22.352 .367,27$ & $96.842 .134,35$ \\
\hline M22 & $\begin{array}{l}\text { Pinto } \\
\text { Bandeira }\end{array}$ & $9.860 .461,18$ & $9.880 .225,84$ & $11.402 .061,30$ & $11.714 .008,97$ & $12.820 .663,59$ & $55.677 .420,88$ \\
\hline M23 & $\begin{array}{l}\text { Protásio } \\
\text { Alves }\end{array}$ & $10.042 .902,19$ & $10.456 .670,26$ & $12.004 .524,39$ & $11.952 .355,15$ & $13.195 .150,56$ & $57.651 .602,55$ \\
\hline M24 & Santa Tereza & $8.830 .633,44$ & $9.365 .671,25$ & $10.511 .505,19$ & $10.339 .322,38$ & $11.149 .700,55$ & $50.196 .832,81$ \\
\hline M25 & São Jorge & $10.071 .207,50$ & $10.633 .918,16$ & $12.079 .234,76$ & $12.115 .219,81$ & $13.149 .614,19$ & $58.049 .194,42$ \\
\hline M26 & São Marcos & $35.099 .127,45$ & $37.664 .667,11$ & $41.216 .794,11$ & $41.993 .510,66$ & $45.096 .676,62$ & $201.070 .775,95$ \\
\hline M27 & $\begin{array}{l}\text { São Valentim } \\
\text { d S }\end{array}$ & $9.574 .759,18$ & $9.893 .679,83$ & $11.327 .489,38$ & $11.409 .731,52$ & $12.344 .003,41$ & $54.549 .663,32$ \\
\hline M28 & $\begin{array}{l}\text { Serafina } \\
\text { Corrêa }\end{array}$ & $30.100 .357,46$ & $31.773 .256,46$ & $36.587 .757,26$ & $37.543 .279,00$ & $39.756 .308,32$ & $175.760 .958,50$ \\
\hline M29 & $\begin{array}{l}\text { União da } \\
\text { Serra }\end{array}$ & $9.872 .901,69$ & $10.224 .723,98$ & $11.567 .657,44$ & $11.431 .714,69$ & $12.433 .758,34$ & $55.530 .756,14$ \\
\hline M30 & Veranópolis & $48.903 .857,64$ & $51.633 .067,52$ & $55.303 .992,92$ & $57.593 .959,54$ & $61.640 .241,27$ & $275.075 .118,89$ \\
\hline M31 & Vila Flores & $12.348 .014,31$ & $13.742 .001,08$ & $15.605 .782,12$ & $15.726 .410,01$ & $17.008 .868,54$ & $74.431 .076,06$ \\
\hline M32 & $\begin{array}{l}\text { Vista Alegre } \\
\text { do Prata }\end{array}$ & $10.163 .035,73$ & $11.012 .956,28$ & $13.216 .316,46$ & $13.273 .481,22$ & 13.643 .832 .46 & $47.665 .789,69$ \\
\hline & Total & $\mathbf{1 . 7 6 9 . 5 5 0 . 2 9 8 , 1 1}$ & $\mathbf{1 . 8 3 5 . 9 7 4 . 8 7 2 , 9 6}$ & $\mathbf{2 . 0 1 3 . 6 6 2 . 9 2 5 , 1 3}$ & $\mathbf{2 . 0 4 8 . 0 5 8 . 6 3 6 , 9 8}$ & $\mathbf{2 . 1 7 9 . 4 7 0 . 7 9 3 , 6 6}$ & $\mathbf{9 . 8 4 7 . 8 2 4 . 1 8 1 , 4 6}$ \\
\hline
\end{tabular}

Fonte: elaborado pelos autores com base em TCE/RS (2019).

Em conformidade com os dados apresentados na tabela 4 pode-se observar a representatividade anual de cada município em relação à arrecadação e a aplicação das receitas municipais, sobre os respectivos anos analisados. Caxias do Sul destaca-se por representar $44,20 \%$ da arrecadação total, seguido de Bento Gonçalves representando $11,29 \%$ e Farroupilha, com $6,44 \%$ do montante da arrecadação. Em contrapartida salienta-se que os municípios de Vista Alegre do Prata possuem representatividade de $0,48 \%$ do total de arrecadação seguido de Santa Tereza, com 0,51\%, e Guabiju, com 0,52\% do montante da arrecadação do município.

\section{Despesas aplicadas em manutenção e desenvolvimento do ensino}

Apresenta-se as despesas relacionadas ao período dos últimos cinco anos dos 32 municípios da Serra Gaúcha, sendo estas aplicadas na manutenção e desenvolvimento do ensino.

As despesas aqui apresentadas foram extraídas do Portal do Tribunal de Contas do Estado do Rio Grande do Sul (TCE/RS, 2019). Destaca-se que os valores elencados correspondem ao valor total das despesas liquidadas, ou seja, as despesas pagas no período analisado, independente do exercício aos quais as foram empenhadas. Na tabela 5 encontram-se os municípios analisados em ordem alfabética, informando as despesas aplicadas em cada período.

Quadro 5 -

Despesas aplicadas em manutenção e desenvolvimento do ensino $(R \$)$.

\begin{tabular}{|l|l|r|r|r|r|r|r|}
\hline Cód. & Municípios & \multicolumn{1}{c|}{2014} & \multicolumn{1}{c|}{2015} & \multicolumn{1}{c|}{2016} & \multicolumn{1}{c|}{2017} & \multicolumn{1}{c|}{2018} & \multicolumn{1}{c|}{ Total } \\
\hline M1 & Antônio Prado & $6.305 .108,91$ & $6.645 .237,80$ & $7.860 .093,10$ & $8.428 .459,38$ & $8.763 .823,16$ & $38.002 .722,35$ \\
\hline M2 & $\begin{array}{l}\text { Bento } \\
\text { Gonçalves }\end{array}$ & $66.825 .588,87$ & $69.910 .227,68$ & $72.186 .425,51$ & $81.240 .070,93$ & $73.733 .729,49$ & $363.896 .042,48$ \\
\hline M3 & $\begin{array}{l}\text { Boa Vista do } \\
\text { Sul }\end{array}$ & $3.615 .378,05$ & $3.862 .295,41$ & $4.369 .160,55$ & $4.620 .271,35$ & $4.799 .737,98$ & $21.266 .843,34$ \\
\hline
\end{tabular}

\begin{tabular}{|l|l|l|l|l|r|} 
Regae: Rev. Gest. Aval. Educ. & Santa Maria & v. 9 & n. 18 & Pub. contínua 2020 & p. $1-23$
\end{tabular}




\begin{tabular}{|c|c|c|c|c|c|c|c|}
\hline M4 & \begin{tabular}{|l} 
Carlos \\
Barbosa \\
\end{tabular} & $17.475 .174,25$ & $18.033 .205,75$ & $20.678 .570,74$ & $21.684 .522,85$ & $24.658 .280,53$ & $102.529 .754,12$ \\
\hline M5 & Caxias do Sul & $207.154 .063,58$ & $232.080 .811,24$ & $248.762 .887,04$ & $243.313 .240,25$ & $257.105 .359,74$ & $1.188 .416 .361,85$ \\
\hline M6 & Coronel Pilar & 2.423.311,97 & $2.620 .785,62$ & $2.900 .755,05$ & $2.871 .701,10$ & $3.129 .588,14$ & $13.946 .141,88$ \\
\hline M7 & Cotiporã & $3.555 .839,90$ & $3.571 .263,42$ & $3.997 .304,57$ & $4.049 .548,73$ & $4.312 .145,76$ & $19.486 .102,38$ \\
\hline M8 & \begin{tabular}{|l|} 
Fagundes \\
Varela
\end{tabular} & $3.264 .802,42$ & $3.485 .644,28$ & $3.898 .621,03$ & $3.769 .646,99$ & $4.197 .579,49$ & 18.616.294,21 \\
\hline M9 & Farroupilha & $37.454 .442,56$ & $35.063 .553,40$ & $36.635 .891,39$ & $39.688 .619,32$ & $39.830 .391,65$ & $188.672 .898,32$ \\
\hline M10 & \begin{tabular}{|l|}
$\begin{array}{l}\text { Flores da } \\
\text { Cunha }\end{array}$ \\
\end{tabular} & $16.779 .608,05$ & $17.712 .883,50$ & $20.109 .448,99$ & $20.396 .169,10$ & $21.014 .619,23$ & $96.012 .728,87$ \\
\hline M11 & Garibaldi & $18.961 .193,69$ & $20.589 .573,38$ & 22.632.232,15 & $22.975 .085,61$ & $23.095 .755,22$ & $108.253 .840,05$ \\
\hline M12 & Guabiju & $2.303 .410,55$ & $2.331 .812,30$ & $2.767 .494,68$ & $2.684 .770,96$ & $3.043 .066,02$ & $13.130 .554,51$ \\
\hline M13 & Guaporé & $10.447 .505,77$ & $11.073 .130,31$ & $12.045 .988,20$ & $13.357 .474,59$ & $13.537 .513,51$ & $60.461 .612,38$ \\
\hline M14 & Montauri & $2.984 .304,41$ & $2.995 .737,53$ & $3.290 .745,51$ & $3.290 .810,15$ & $3.543 .355,20$ & $16.104 .952,80$ \\
\hline M15 & $\begin{array}{l}\text { Monte Belo } \\
\text { do Sul }\end{array}$ & $3.584 .636,88$ & $3.910 .080,35$ & $3.954 .203,87$ & $3.807 .298,90$ & $3.636 .030,43$ & $18.892 .250,43$ \\
\hline M16 & Nova Araçá & $4.013 .561,27$ & $4.214 .435,70$ & $4.380 .260,79$ & $4.644 .057,14$ & $5.014 .852,69$ & $22.267 .167,59$ \\
\hline M17 & \begin{tabular}{|l|} 
Nova \\
Bassano \\
\end{tabular} & $6.061 .879,76$ & $6.362 .595,57$ & $7.044 .034,66$ & $7.630 .063,86$ & $7.202 .366,24$ & $34.300 .940,09$ \\
\hline M18 & Nova Pádua & $2.867 .423,98$ & $3.273 .933,69$ & $3.873 .879,56$ & $3.466 .536,15$ & $3.999 .047,48$ & $17.480 .820,86$ \\
\hline M19 & Nova Prata & $13.127 .043,01$ & $16.052 .216,28$ & $17.684 .920,21$ & $18.958 .981,43$ & $20.024 .811,55$ & $85.847 .972,48$ \\
\hline M20 & $\begin{array}{l}\text { Nova Roma } \\
\text { do Sul }\end{array}$ & $4.342 .664,75$ & $4.379 .993,86$ & $5.975 .375,70$ & $4.687 .582,95$ & $4.872 .476,55$ & $24.258 .093,81$ \\
\hline M21 & Paraí & 4.333.296,15 & $4.516 .872,36$ & $5.003 .426,54$ & $5.618 .578,77$ & $6.010 .645,78$ & $25.482 .819,60$ \\
\hline M22 & \begin{tabular}{|l|} 
Pinto \\
Bandeira \\
\end{tabular} & $2.627 .474,83$ & $2.874 .592,07$ & $3.534 .266,41$ & $3.132 .163,98$ & $3.661 .607,12$ & $15.830 .104,41$ \\
\hline M23 & \begin{tabular}{|l|} 
Protásio \\
Alves \\
\end{tabular} & $3.165 .409,23$ & $3.070 .019,35$ & $3.365 .402,39$ & $3.402 .764,41$ & $3.538 .416,65$ & $16.542 .012,03$ \\
\hline M24 & Santa Tereza & $2.674 .675,85$ & $3.225 .245,19$ & $3.278 .016,83$ & $3.399 .596,41$ & $3.677 .820,23$ & $16.255 .354,51$ \\
\hline M25 & São Jorge & $2.765 .663,39$ & $2.915 .888,50$ & 3.163.248,43 & $3.719 .660,33$ & $4.020 .482,68$ & $16.584 .943,33$ \\
\hline M26 & São Marcos & $9.682 .625,77$ & $11.850 .957,72$ & $13.133 .667,43$ & $14.319 .985,58$ & $13.700 .084,69$ & $62.687 .321,19$ \\
\hline M27 & $\begin{array}{l}\text { São Valentim } \\
\text { d S }\end{array}$ & $2.421 .900,71$ & $2.552 .926,47$ & $2.943 .852,08$ & $3.024 .401,36$ & $3.300 .447,29$ & $14.243 .527,91$ \\
\hline M28 & \begin{tabular}{|l|} 
Serafina \\
Corrêa
\end{tabular} & $8.975 .765,74$ & $8.747 .653,30$ & $11.119 .940,77$ & $10.622 .677,04$ & $10.415 .942,94$ & $49.881 .979,79$ \\
\hline M29 & \begin{tabular}{|l|} 
União da \\
Serra \\
\end{tabular} & $2.920 .230,93$ & $2.837 .234,83$ & $3.148 .731,70$ & $3.181 .258,33$ & $3.215 .003,33$ & $15.302 .459,12$ \\
\hline M30 & Veranópolis & $13.241 .009,50$ & $13.953 .528,02$ & $14.961 .019,33$ & $14.715 .156,74$ & $15.956 .351,47$ & $72.827 .065,06$ \\
\hline M31 & Vila Flores & $3.258 .322,60$ & $3.733 .077,51$ & $4.236 .422,95$ & $4.254 .150,13$ & $4.663 .033,82$ & $20.145 .007,01$ \\
\hline \multirow[t]{2}{*}{ M32 } & $\begin{array}{l}\text { Vista Alegre } \\
\text { do Prata }\end{array}$ & $2.690 .129,96$ & $2.930 .929,93$ & $3.355 .108,68$ & $3.474 .599,72$ & $3.694 .844,97$ & $16.145 .613,26$ \\
\hline & Total & $492.303 .447,29$ & $531.378 .342,32$ & $576.291 .396,84$ & $588.429 .904,54$ & $605.369 .211,03$ & 2.793.772.302,02 \\
\hline
\end{tabular}

Fonte: elaborada pela autora conforme dados disponibilizados no Portal do TCE/RS (2019).

Em conformidade aos dados apresentados na tabela 5 observa-se a representatividade dos municípios em relação a manutenção e desenvolvimento do ensino no período de 2014 a 2018. O município de Caxias do Sul referencia-se por representar o percentual de $42,54 \%$ em relação às despesas aplicadas, seguido de Bento Gonçalves com 13,03\% do montante aplicado em MDE, e Farroupilha, com 6,75\% de aplicação em manutenção e desenvolvimento do ensino. 
Em contrapartida, salienta-se que entre os municípios os quais evidenciam a menor representatividade encontra-se o município de Guabiju, com 0,47\%, seguido de Coronel Pilar, com $0,50 \%$, e São Valentim do Sul, com $0,51 \%$ do montante aplicado em manutenção e desenvolvimento do ensino.

Na Figura 1 apresenta-se a evolução total das despesas aplicadas em manutenção e desenvolvimento do ensino no decorrer dos anos de 2014 a 2018.

Figura 1 -

Evolução das despesas aplicadas em MDE.

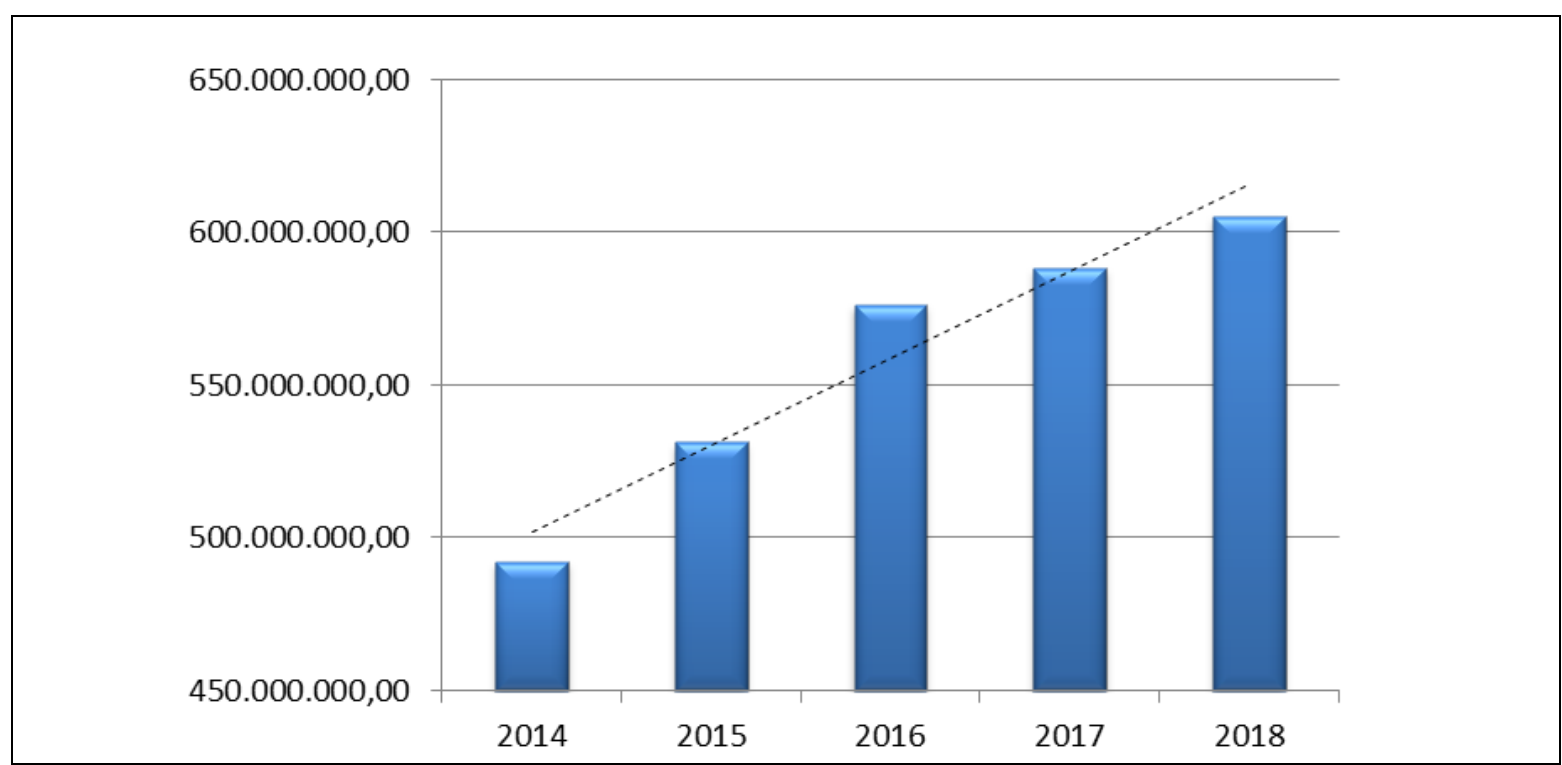

Fonte: elaborada pelos autores. A linha tracejada representa a tendência.

$\mathrm{Na}$ mesma medida em que as variações tornam-se positivas, e com tendência de crescimento, indicadores nacionais evidenciam que os investimentos em educação básica tornam-se cada vez menores. De acordo com dados divulgados o valor investido com a educação no Brasil teve queda de $56 \%$ nos últimos quatro anos, sendo que na educação básica entre os anos de 2014 a 2018 o investimento passou de $R \$ 36,2$ bilhões para $R \$$ 29,3 bilhões, resultando numa variação decrescente de 19\% (UOL, 2019). Evidencia-se, portanto, que os dados nacionais estão na contramão em relação aos apresentados na presente pesquisa, em que as aplicações em manutenção e desenvolvimento do ensino encontram-se evoluindo positivamente entre os anos analisados.

\section{Aplicação de recursos em MDE}

Apresenta-se a seguir os percentuais encontrados em relação à aplicação na manutenção e desenvolvimento do ensino nos 32 municípios analisados na Serra Gaúcha. Os percentuais de aplicação aqui demonstrados foram calculados embasados na receita líquida de impostos e transferências e nas despesas aplicadas na manutenção e desenvolvimento do ensino. Estes dados foram extraídos do Portal do TCE/RS (2019). Na tabela 6 evidenciam-se os percentuais encontrados seguidos do percentual médio aplicado em cada município no período de 2014 a 2018. 
Tabela 6 -

Percentuais das Receitas aplicadas em MDE (\%).

\begin{tabular}{|c|c|c|c|c|c|c|c|}
\hline Cód. & Municípios & 2014 & 2015 & 2016 & 2017 & 2018 & Média \\
\hline M1 & Antônio Prado & 26,72 & 26,22 & 27,63 & 28,71 & 27,03 & 27,26 \\
\hline $\mathrm{M} 2$ & Bento Gonçalves & 33,27 & 33,87 & 32,81 & 34,30 & 29,75 & 32,80 \\
\hline M3 & Boa Vista do Sul & 27,09 & 27,94 & 28,07 & 29,26 & 27,71 & 28,01 \\
\hline M4 & Carlos Barbosa & 26,82 & 25,78 & 25,81 & 25,57 & 26,03 & 26,00 \\
\hline M5 & Caxias do Sul & 25,63 & 27,61 & 27,76 & 27,72 & 27,64 & 27,27 \\
\hline M6 & Coronel Pilar & 25,21 & 26,16 & 25,70 & 25,57 & 25,89 & 25,71 \\
\hline M7 & Cotiporã & 26,89 & 26,06 & 25,95 & 25,87 & 25,37 & 26,03 \\
\hline M8 & Fagundes Varela & 29,39 & 30,63 & 30,17 & 28,67 & 29,03 & 29,58 \\
\hline M9 & Farroupilha & 33,77 & 30,93 & 29,05 & 29,55 & 26,67 & 29,99 \\
\hline M10 & Flores da Cunha & 29,28 & 29,23 & 29,48 & 28,40 & 26,99 & 28,68 \\
\hline M11 & Garibaldi & 28,00 & 28,82 & 28,93 & 28,46 & 25,67 & 27,98 \\
\hline M12 & Guabiju & 26,08 & 25,14 & 25,97 & 25,22 & 25,69 & 25,62 \\
\hline M13 & Guaporé & 26,33 & 26,31 & 25,28 & 26,93 & 25,16 & 26,00 \\
\hline M14 & Montauri & 28,63 & 28,06 & 27,57 & 27,70 & 27,84 & 27,96 \\
\hline M15 & Monte Belo do Sul & 31,13 & 32,16 & 29,55 & 29,61 & 27,04 & 29,90 \\
\hline M16 & Nova Araçá & 28,70 & 28,41 & 26,93 & 27,72 & 27,74 & 27,90 \\
\hline M17 & Nova Bassano & 25,63 & 25,11 & 25,19 & 25,51 & 25,48 & 25,38 \\
\hline M18 & Nova Pádua & 26,15 & 28,72 & 30,47 & 26,88 & 28,18 & 28,08 \\
\hline M19 & Nova Prata & 30,53 & 33,47 & 33,26 & 31,99 & 30,79 & 32,01 \\
\hline M20 & Nova Roma do Sul & 29,60 & 28,49 & 34,65 & 26,90 & 25,87 & 29,10 \\
\hline M21 & Paraí & 25,37 & 25,55 & 25,78 & 27,65 & 26,89 & 26,25 \\
\hline M22 & Pinto Bandeira & 26,65 & 29,09 & 31,00 & 26,74 & 28,56 & 28,41 \\
\hline M23 & Protásio Alves & 31,52 & 29,36 & 28,03 & 28,47 & 26,82 & 28,84 \\
\hline M24 & Santa Tereza & 30,29 & 34,44 & 31,19 & 32,88 & 32,99 & 32,36 \\
\hline M25 & São Jorge & 27,46 & 27,42 & 26,19 & 30,70 & 30,57 & 28,47 \\
\hline M26 & São Marcos & 27,59 & 31,46 & 31,86 & 34,10 & 30,38 & 31,08 \\
\hline M27 & São Valentim do Sul & 25,29 & 25,80 & 25,99 & 26,51 & 26,74 & 26,07 \\
\hline M28 & Serafina Corrêa & 29,82 & 27,53 & 30,39 & 28,29 & 26,20 & 28,45 \\
\hline M29 & União da Serra & 29,58 & 27,75 & 27,22 & 27,83 & 25,86 & 27,65 \\
\hline M30 & Veranópolis & 27,08 & 27,02 & 27,05 & 25,55 & 25,89 & 26,52 \\
\hline M31 & Vila Flores & 26,39 & 27,17 & 27,15 & 27,05 & 27,42 & 27,04 \\
\hline M32 & Vista Alegre do Prata & 26,47 & 26,61 & 25,39 & 26,18 & 27,08 & 26,35 \\
\hline \multicolumn{2}{|c|}{ Média Anual } & 28,07 & 28,39 & 28,36 & 28,20 & 27,41 & 28,09 \\
\hline
\end{tabular}

Fonte: elaborada pelos autores com base em TCE/RS (2019).

Os dados mencionados na tabela 6 , referentes à média, foram obtidos pelos somatórios dos percentuais de cada ano em seu respectivo município, sendo que o valor encontrado foi dividido pela quantidade de anos analisados. A média anual, por sua vez, foi obtida pelo somatório de todos os percentuais dos municípios em determinado ano e dividido pelos 32 municípios analisados. Ao analisar os percentuais encontrados observa- 
se que todos os municípios respeitam o que está previsto no artigo 212 da CF de 1988, ou seja, aplica-se um percentual mínimo de $25 \%$ da receita líquida na educação dos respectivos municípios.

Entre os municípios analisados, alguns se destacam por aplicar percentuais maiores: Nova Roma do Sul em 2016 aplicou 34,65\% da receita líquida, consequentemente este é o município com maior percentual de aplicação em manutenção e desenvolvimento do ensino nos respectivos anos analisados. Na sequência vem o município de Santa Tereza, que em 2015 aplicou o percentual de 34,44\%, seguido de Bento Gonçalves, que em 2017 aplicou o percentual de 34,30\%, enquanto que São Marcos aplicou em 2017 o percentual de $34,10 \%$ da receita líquida em MDE.

Por outro lado, o município de Nova Bassano caracteriza-se por aplicar o menor percentual em MDE: 25,11\% no ano de 2015, seguido de Guabiju, que aplicou 25,14\% da receita líquida no ano de 2015, e o município de Guaporé, que no ano de 2018 aplicou o percentual de $25,16 \%$.

De forma geral pode-se mencionar que a média total anual oscilou de um ano para o outro. Em relação ao ano de 2014 para 2015, obteve uma ligeira elevação: inicialmente estava em 28,07\% passando para 28,39\%. Enquanto que no ano de 2016 obteve uma ligeira queda ficando em $28,36 \%$, este fato seguiu nos anos seguintes: observa-se que em 2017 atingiu o percentual de 28,20\% e em 2018 ficou em 27,41\% do total da média anual. Verifica-se assim uma diminuição na aplicação em manutenção e desenvolvimento do ensino no período de 2014 a 2018.

Relacionando-se a estas informações e para que se tenha um melhor entendimento dos percentuais médios anuais encontrados nos cinco anos de análise, demonstra-se na figura 2 a trajetória da média anual nos 32 municípios da Serra Gaúcha.

Figura 2 -

Trajetória da média anual aplicada em MDE nos 32 municípios.

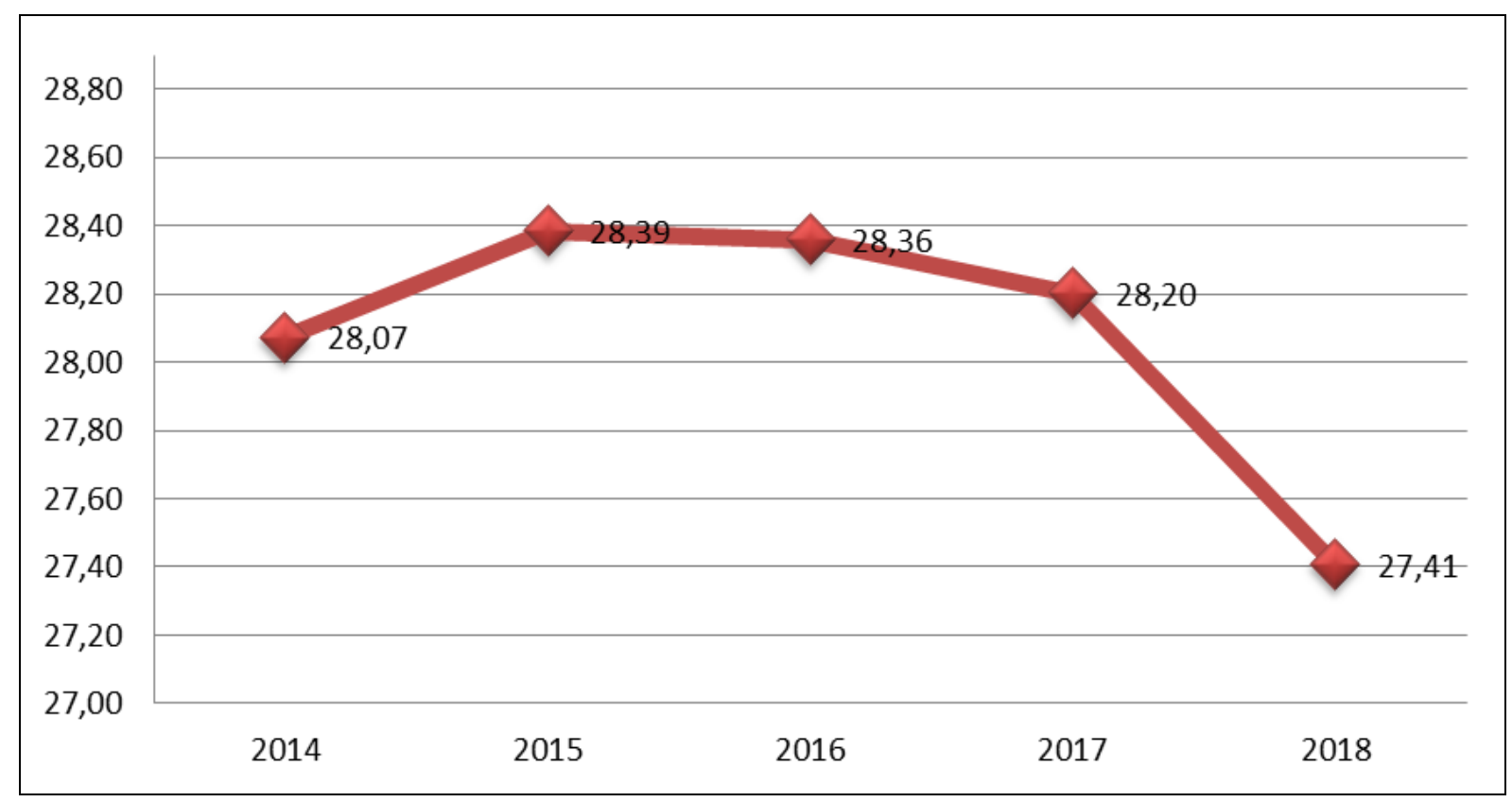

Fonte: elaborada pelos autores. 
Evidenciando-se as informações anteriormente citadas, e para que se tenha uma melhor visualização das médias gerais, ilustra-se os percentuais de cada município em ordem decrescente na figura 3.

Figura 3 -

Percentuais médios de aplicação dos recursos em MDE.

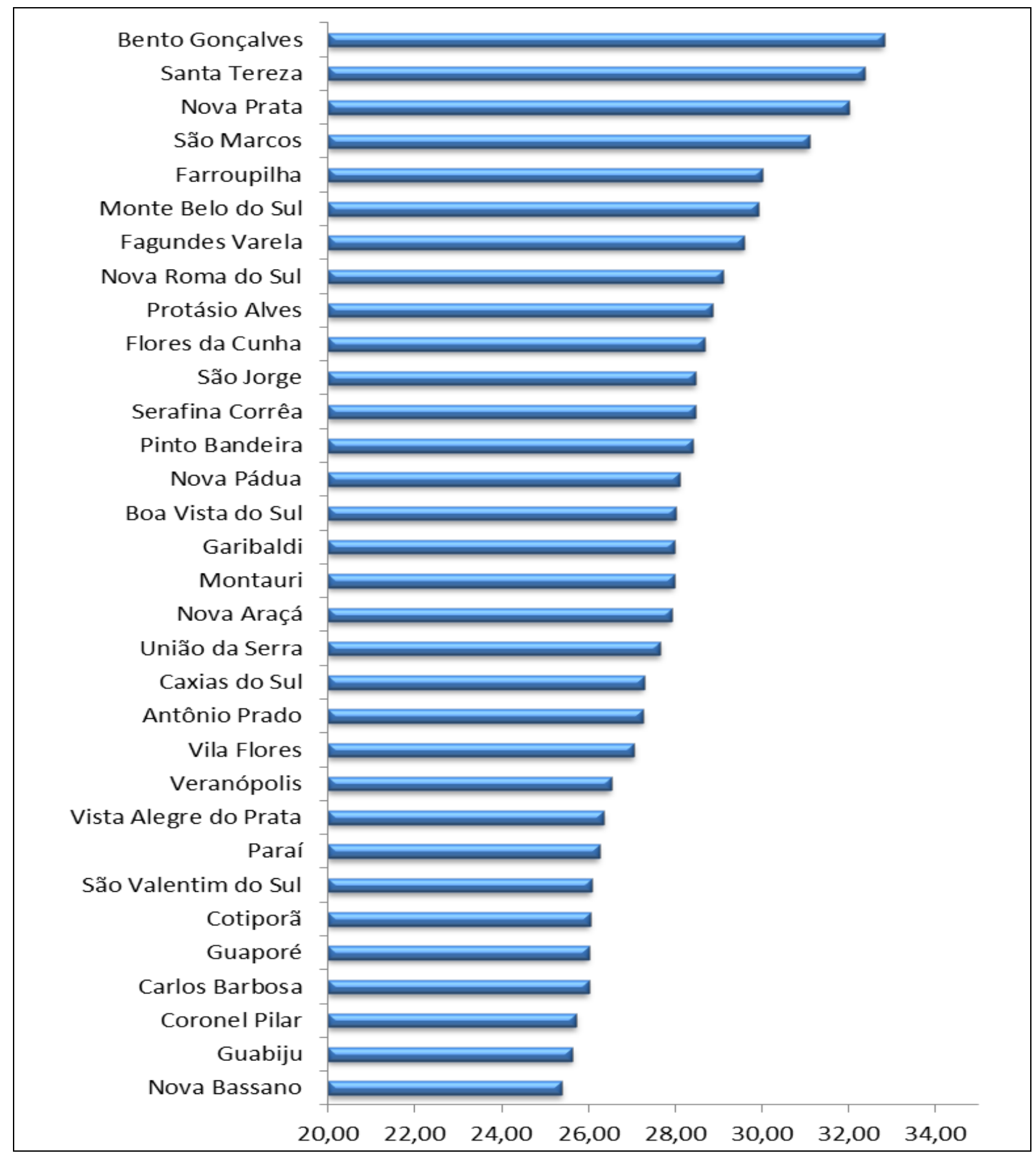

Fonte: elaborada pelos autores.

Em conformidade a figura 3 observa-se que, dos anos analisados, o município de Bento Gonçalves destaca-se por atingir o maior percentual em média de aplicação em manutenção e desenvolvimento do ensino: $32,80 \%$ da receita líquida. Em contrapartida, o 
município de Nova Bassano apresentou o percentual médio de 25,38\%, elencando-se como sendo a menor aplicação em média entre os municípios, o que caracteriza-se numa diferença de 7,42 pontos percentuais a menor em relação ao município de Bento Gonçalves.

\section{Gasto na MDE versus desempenho no Ideb}

Para que se possa analisar a qualidade da educação básica nos municípios da Serra Gaúcha, se faz necessário à apresentação dos resultados encontrados no Índice de Desenvolvimento da Educação Básica - Ideb -, dos 32 municípios analisados, estes dados foram coletados no Portal do Ideb (Ideb, 2019). Apresenta-se a pontuação disponível no ano de 2017.

Lembra-se ainda que a participação das escolas é voluntária, sendo assim, se a escola optar por não participar da avaliação, a mesma não possuirá pontuação no ldeb neste período. Encontra-se ainda a possibilidade de, em alguns anos mesmo a escola optando em participar, não possuir a quantidade mínima de alunos, o que também implica em não obter resultados na participação do Índice de Desenvolvimento na Educação Básica. Ressalta-se também que esta avaliação encontra-se em um indicador de pontuação entre zero e dez.

Para melhor compreensão e análise, apresenta-se na tabela 7 os dados referentes ao ano de 2017, fazendo-se um comparativo com os percentuais aplicados em manutenção e desenvolvimento do ensino nos respectivos municípios. Na apresentação do Ideb, nos municípios referentes ao ano de 2017, utilizou-se o critério da média entre as etapas pertencentes à educação básica, ou seja, pré-escola, ensino fundamental e ensino médio. A ordem dos municípios no referido quadro respeita o percentual aplicado em manutenção e desenvolvimento do ensino.

Tabela 7 -

Comparativo de aplicação em MDE versus Ideb 2017.

\begin{tabular}{|c|c|c|c|c|c|}
\hline & & \multicolumn{2}{|c|}{ MDE - 2017} & \multicolumn{2}{|c|}{ Ideb - 2017} \\
\hline Cód. & Municípios & $\%$ & Colocação & Nota & Colocação \\
\hline M2 & Bento Gonçalves & 34,30 & $1^{\circ}$ & 4.90 & $25^{\circ}$ \\
\hline M26 & São Marcos & 34,10 & $2^{0}$ & 6.15 & $3^{\circ}$ \\
\hline M24 & Santa Tereza & 32,88 & $3^{\circ}$ & 6.20 & $2^{0}$ \\
\hline M19 & Nova Prata & 31,99 & $4^{0}$ & 5.00 & $23^{\circ}$ \\
\hline M25 & São Jorge & 30,70 & 5은 & 4.90 & $27^{\circ}$ \\
\hline M15 & Monte Belo do Sul & 29,61 & $6^{\circ}$ & 4.75 & $30^{\circ}$ \\
\hline M9 & Farroupilha & 29,55 & $7^{0}$ & 5.53 & $10^{\circ}$ \\
\hline M3 & Boa Vista do Sul & 29,26 & $8^{\circ}$ & 5.50 & $12^{\circ}$ \\
\hline M1 & Antônio Prado & 28,71 & $9^{\circ}$ & 4.77 & $29^{\circ}$ \\
\hline M8 & Fagundes Varela & 28,67 & $10^{\circ}$ & 5.27 & $15^{\circ}$ \\
\hline M23 & Protásio Alves & 28,47 & $11^{\circ}$ & 4.73 & $31^{\circ}$ \\
\hline M11 & Garibaldi & 28,46 & $12^{\circ}$ & 5.03 & $21^{\circ}$ \\
\hline M10 & Flores da Cunha & 28,40 & $13^{\circ}$ & 5.70 & $6^{0}$ \\
\hline M28 & Serafina Corrêa & 28,29 & $14^{\circ}$ & 5.10 & $19^{\circ}$ \\
\hline M29 & União da Serra & 27,83 & $15^{\circ}$ & 5.20 & $16^{\circ}$ \\
\hline M5 & Caxias do Sul & 27,72 & $17^{\circ}$ & 4.80 & $28^{\circ}$ \\
\hline M16 & Nova Araçá & 27,72 & $16^{\circ}$ & 5.07 & $20^{\circ}$ \\
\hline M14 & Montauri & 27,70 & $18^{\circ}$ & 6.07 & $4^{\circ}$ \\
\hline
\end{tabular}




\begin{tabular}{|c|c|c|c|c|c|}
\hline M21 & Paraí & 27,65 & $19^{\circ}$ & 5.33 & $14^{\circ}$ \\
\hline M31 & Vila Flores & 27.05 & $20^{\circ}$ & 5.13 & $18^{\circ}$ \\
\hline M13 & Guaporé & 26,93 & $21^{\circ}$ & 5.00 & $22^{\circ}$ \\
\hline M20 & Nova Roma do Sul & 26,90 & $22^{\circ}$ & 5.60 & 90 \\
\hline M18 & Nova Pádua & 26,88 & $23^{\circ}$ & 5.53 & $11^{\circ}$ \\
\hline M22 & Pinto Bandeira & 26,74 & $24 \div$ & 4.50 & $32^{\circ}$ \\
\hline M27 & São Valentim do Sul & 26,51 & $25^{\circ}$ & 5.63 & $7^{0} \underline{0}$ \\
\hline M32 & Vista Alegre do Prata & 26,18 & $26^{\circ}$ & 5.20 & $17^{\circ}$ \\
\hline M7 & Cotiporã & 25,87 & $27^{\circ}$ & 5.73 & $5^{\circ}$ \\
\hline M4 & Carlos Barbosa & 25,57 & $29^{\circ}$ & 5.60 & $8^{\circ}$ \\
\hline M6 & Coronel Pilar & 25,57 & $28^{\circ}$ & 6.30 & $1^{0}$ \\
\hline M30 & Veranópolis & 25,55 & $30^{\circ}$ & 5.00 & $24^{\circ}$ \\
\hline M17 & Nova Bassano & 25,51 & $31^{\circ}$ & 4.90 & $26^{\circ}$ \\
\hline M12 & Guabiju & 25,22 & $32^{\circ}$ & 5.50 & $13^{\circ}$ \\
\hline
\end{tabular}

Fonte: Ideb (2019), adaptado pelos autores.

Em conformidade com a tabela 7, quando observa-se o percentual de aplicação em manutenção e desenvolvimento do ensino, o município o qual destaca-se por atingir a $1^{\underline{a}}$ colocação, no ano de 2017, é o município de Bento Gonçalves, aplicando o percentual de $34,30 \%$ da arrecadação em educação, o que implica em 9,30 pontos percentuais acima do mínimo recomendado pela Constituição Federal. No entanto, quando analisa-se a pontuação de Bento Gonçalves no Ideb, este atinge a média de 4.90 no ano de 2017, o que implica na $25^{\mathrm{a}}$ colocação na prova avaliativa.

Por outro lado, Guabiju encontra-se como sendo o município que aplica o menor percentual em MDE, ou seja, $25,22 \%$ no ano de 2017 , enquadrando-se, assim, na $32^{\mathrm{a}}$ colocação. Em compensação, ao analisar-se a pontuação de Guabiju no Ideb, este atinge em média 5.50 pontos: $13^{\mathrm{a}}$ colocação. Neste caso, mesmo Bento Gonçalves aplicando um percentual superior em MDE, sua pontuação em média no Índice do Desenvolvimento da Educação é inferior ao de Guabiju, ou seja, 0,60 pontos percentuais menor, no ano de 2017.

Paralelo as informações mencionadas anteriormente, e ainda com base na tabela 7 , quando analisa-se o Ideb, observa-se que o município o qual destaca-se por atingir a $1^{\underline{a}}$ colocação e possuir a maior média, na prova avaliativa, ou seja, 6.30, é Coronel Pilar. Por sua vez, este aplicou o percentual de $25,57 \%$ em manutenção e desenvolvimento do ensino no ano de 2017, o que implica em 0,57 pontos percentuais acima do mínimo recomendado pela Constituição Federal.

Já no outro extremo encontra-se o município de Pinto Bandeira, que possui a menor média no Ideb, ou seja, 4.50 , e aplica o percentual de $26,74 \%$ em MDE, o que implica em 1,74 pontos percentuais acima do mínimo recomendado. Desta forma, observa-se neste caso que, mesmo aplicando um percentual superior ao município de Coronel Pilar, Pinto Bandeira encontra-se com pontuação inferior no Ideb, implicando assim na $32^{\mathrm{a}}$ colocação na prova avaliativa do Ideb, no referido ano de 2017.

Percebe-se, portanto, que nem sempre as maiores aplicações retribuem na melhor qualificação do ensino na educação básica nos municípios analisados. Neste grupo o município de Monte Belo do Sul ocupa a terceira colocação em relação à média da nota no Ideb - 4.75 -, em contrapartida aplica o maior percentual em MDE, ou seja, 29,61\% da 
receita líquida. Ressalta-se que o município de Pinto Bandeira classifica-se por possuir a menor pontuação no Ideb 2017, ou seja, 4.5 e consequentemente, a menor aplicação em manutenção e desenvolvimento do ensino.

\section{Considerações finais}

A partir das informações e cálculos vistos anteriormente torna-se possível tecer algumas considerações sobre os municípios analisados. Por exemplo, quando mencionase os valores gastos com manutenção e desenvolvimento do ensino o município de Caxias do Sul referencia-se por representar o percentual de $42,54 \%$, seguido de Bento Gonçalves, com 13,03\% do montante, e o município de Farroupilha, com percentual de $6,75 \%$. Por outro lado, os municípios que enquadram-se com as menores representatividades são Guabiju, 0,47\%, seguido de Coronel Pilar, 0,50\%, e São Valentim do Sul, com $0,51 \%$ do montante aplicado em manutenção e desenvolvimento do ensino.

Enquanto isso, quando analisa-se os percentuais aplicados em manutenção e desenvolvimento do ensino constatou-se que todos os municípios analisados respeitam os percentuais impostos pela Constituição Federal de 1988, ou seja, aplicam percentuais mínimos superiores a $25 \%$ da receita líquida.

O maior percentual aplicado encontra-se no município de Nova Roma do Sul que, no ano de 2016 aplicou 34,65\%, seguido de Santa Tereza, que em 2015 aplicou o percentual de 34,44\%, e Bento Gonçalves, que no ano de 2017 aplicou o percentual de 34,30\% da receita líquida. No outro extremo encontra-se o município de Nova Bassano, que aplicou o menor percentual, 25,11\%, no ano de 2015, seguido de Guabiju, que aplicou 25,14\% da receita líquida no ano de 2015, e o município de Guaporé, que no ano de 2018 aplicou o percentual de $25,16 \%$.

Ao analisar-se os percentuais médios encontrados entre os anos de 2014 a 2018 nos respectivos municípios, destacou-se entre os municípios Bento Gonçalves, este com o maior percentual médio aplicado, $32,80 \%$ da receita líquida, seguido de Santa Tereza, com percentual médio de 32,36\%, e o município de Nova Prata, com 32,01\% de percentual médio. Já no outro extremo encontra-se o município de Nova Bassano, com o menor percentual médio aplicado, 25,38\% da receita líquida, seguido de Guabiju, com percentual médio de 25,62\%, e Coronel Pilar, com 25,71\% de percentual médio aplicado.

Em relação aos percentuais de variação encontrados, quando analisa-se a evolução das despesas aplicadas em manutenção e desenvolvimento do ensino, evidencia-se que a maior parte dos municípios obtiveram variações positivas, apresentando assim aumento nas aplicações. É importante frisar que no ano de 2016, quando comparado ao ano de 2015, este obteve somente variações positivas. Ao analisar-se a variação total anual percebe-se que todas encontram-se positivas, sendo que o ano de 2016 quando comparado a 2015 obteve a maior variação 8,45\%, seguindo com uma ligeira queda nos demais anos, mas mantendo-se positiva.

Analisou-se o Ideb referente ao ano de 2017 com comparativo ao percentual aplicado em MDE no mesmo ano. Dos municípios analisados destaca-se Coronel Pilar por atingir a maior pontuação em média no Ideb - 6.30 -, seguido de Santa Tereza, este que obteve 6.20, e São Marcos com pontuação de 6.15. 
$\mathrm{Na}$ outra extremidade, dentre os municípios que destacam-se por apresentar a menor pontuação, enquadra-se o município de Pinto Bandeira, com média de 4.5, seguido de Protásio Alves, com pontuação de 4.73, e o município de Monte Belo do Sul, com a pontuação de 4.75. Com isso fica evidente que nem sempre as maiores aplicações em manutenção e desenvolvimento do ensino resultam em nas melhores notas em médias encontradas no Ideb.

Para melhor entendimento das considerações finais elencadas, segue na tabela 8 um resumo sobre as mesmas.

Tabela 8 -

Quadro resumo.

\begin{tabular}{|c|c|c|c|c|c|c|c|c|c|}
\hline \multicolumn{10}{|c|}{ Arrecadações totais } \\
\hline \multicolumn{5}{|c|}{ Maiores arrecadações } & \multicolumn{5}{|c|}{ Menores arrecadações } \\
\hline \multicolumn{2}{|c|}{ Municípios } & \multicolumn{2}{|c|}{ Receitas $\mathrm{R} \$$} & $\%$ Amostra & \multicolumn{2}{|c|}{\begin{tabular}{l|l} 
Municípios & \\
\end{tabular}} & \multicolumn{2}{|c|}{ Receitas $\mathrm{R} \$$} & $\%$ Amostra \\
\hline \multicolumn{2}{|l|}{ Caxias do Sul } & \multicolumn{2}{|c|}{$4.352 .839 .154,09$} & 44,20 & \multicolumn{2}{|c|}{ Vista Alegre do Prata } & \multicolumn{2}{|c|}{$47.665 .789,69$} & 0,48 \\
\hline \multicolumn{2}{|c|}{ Bento Gonçalves } & \multicolumn{2}{|c|}{$1.111 .953 .134,60$} & 11,29 & \multicolumn{2}{|l|}{ Santa Tereza } & $50.196 .832,81$ & \multicolumn{2}{|c|}{0,51} \\
\hline \multirow{2}{*}{\multicolumn{2}{|c|}{ Farroupilha }} & \multicolumn{2}{|c|}{$633.998 .667,40$} & 6,44 & \multicolumn{2}{|l|}{ Guabiju } & \multicolumn{2}{|c|}{$51.254 .530,60$} & 0,52 \\
\hline & & \multicolumn{8}{|c|}{ Despesas aplicadas em manutenção e desenvolvimento do ensino \% } \\
\hline \multicolumn{5}{|c|}{ Maiores Despesas } & \multicolumn{5}{|c|}{ Menores Despesas } \\
\hline \multicolumn{2}{|l|}{ Municípios } & Despesas & & $\%$ Amostra & Municípios & & Despesas $\mathrm{F}$ & $\% A$ & mostra \\
\hline Caxias do Sul & & 1.188 .416 & 61,85 & 42,54 & Guabiju & & 13.130 .55 & 4,51 &, 47 \\
\hline Bento Gonçalve & & 363.896. & 42,48 & 13,03 & Coronel Pilar & & 13.946.14 & 1,88 &, 50 \\
\hline Farroupilha & & 188.672. & 98,32 & 6,75 & São Valentim do S & & 14.243 .52 & 7,91 &, 51 \\
\hline & Per & entuais ap & cados $\epsilon$ & em manute & nção e desenvolvime & o do ens & רsino \% & & \\
\hline & Maio & es Percen & lais & & & enores & s Percentua & & \\
\hline Mur & ípios & & Ano & $\%$ & Munic & & \begin{tabular}{l|l} 
& Anc \\
\end{tabular} & & $\%$ \\
\hline Nova Roma do & & & 2016 & 34,6 & Nova Bassanc & & 201 & &, 11 \\
\hline Santa Tereza & & & 2015 & 34,4 & Guabiju & & 201 & &, 14 \\
\hline Bento Gonçalve & & & 2017 & 34,30 & Guaporé & & 201 & &, 16 \\
\hline & ercent & Jais médio & aplicad & dos em man & lutenção e desenvol & iento do & lo ensino \% & & \\
\hline & iores $p$ & ercentuais & nédios & & Mer & es perc & centuais $\mathrm{m}$ & dios & \\
\hline & cípios & & & $\%$ Médio & Mun & jios & & \% Méc & \\
\hline Bento Gonçalve & & & & 32,80 & Nova Bassano & & & 25,3 & \\
\hline Santa Tereza & & & & 32,36 & Guabiju & & & 25,6 & \\
\hline Nova Prata & & & & 32,01 & Coronel Pilar & & & 25,7 & \\
\hline & & Análise & horizon & ntais das $D \epsilon$ & espesas aplicadas er & ADE \% & & & \\
\hline & & & & & nos & & & & \\
\hline Total Anual & 2014 & -2015 & 201 & $15-2016$ & $2016-2017$ & 2017 & -2018 & $2014-$ & 2018 \\
\hline & &, 94 & & 8,45 & 2,11 & & 2,88 & 22 & \\
\hline & & Índice de & Desenv & volvimento d & la Educação Básica & eb 2017 & & & \\
\hline & ores $n$ & otas em m & & & Men & es notas & as em médi & & \\
\hline & Idek & -2017 & MDE & $E-2017$ & & & b - 2017 & MDE & 2017 \\
\hline Municípios & Nota & Coloc. & $\%$ & Coloc. & Municípios & Nota & Coloc. & $\%$ & Colo \\
\hline Coronel Pilar & 6.30 & $1^{0}$ & 25,57 & $28^{\circ}$ & Pinto Bandeira & 4.50 & $32^{\circ}$ & 26,74 & $24^{\circ}$ \\
\hline Santa Tereza & 6.20 & $2^{\circ}$ & 32,88 & $3^{\circ}$ & Protásio Alves & 4.73 & $31^{\circ}$ & 28,47 & $11^{\circ}$ \\
\hline São Marcos & 6.15 & $3^{\circ}$ & 34,10 & $2^{0}$ & Monte Belo do Sul & 4.75 & $30^{\circ}$ & 29,61 & $6^{\circ}$ \\
\hline
\end{tabular}

Fonte: Elaborado pelos autores 
A educação desempenha um papel importante na vida de cada um. É por meio dela que adquire-se conhecimento e compartilha-se aprendizados, construindo-se assim um alicerce na formação tanto individual como em grupo dos cidadãos. Pela implantação da Lei de Responsabilidade Fiscal, da Lei da Transparência e da Lei de Acesso à Informação, fica mais fácil para a população ter acesso às informações públicas, bem como o acompanhamento de seus governantes na aplicação correta dos tributos arrecadados.

Desta forma, no presente estudo ficou evidente que todos os municípios analisados cumprem com a obrigatoriedade de aplicação em manutenção e desenvolvimento do ensino, o percentual mínimo disposto na Constituição Federal, embora haja disparidades entre os municípios analisados.

Observou-se a evolução das despesas aplicadas em MDE nos municípios, sendo ela, na sua grande maioria, positiva, reforçando assim o interesse por parte dos municípios na evolução e melhoria da educação básica. Observou-se a evolução total anual gasta pelos municípios, nestas apesar de encontrarem-se positivas, em alguns anos houve ligeira queda nas mesmas, o que chama a atenção para uma possível diminuição do percentual aplicado com o passar dos anos, mas manteve-se dentro dos limites estipulados.

Já no que refere-se ao Índice de desenvolvimento da Educação Básica observou-se que nem sempre o município que dispõe do maior percentual aplicado em manutenção e desenvolvimento do ensino é o município que dispõe da melhor nota em média na prova avaliativa do Ideb, ou de forma contrária, o que possui o menor percentual de aplicação será o município o qual dispõe da menor média de nota na prova avaliativa do Ideb.

Ou seja, não é possível estabelecer uma relação direta entre os gastos relacionados com a educação básica com o desempenho dos alunos no Índice de Desenvolvimento da Educação Básica. Há diversos outros fatores que podem influenciar no desempenho dos educandos, tais como as estruturas familiares e a qualificação dos professores.

\section{Referências}

ABRAHAM, Marcus. Lei de responsabilidade fiscal comentada. Rio de Janeiro: Forense, 2017.

ANDRADE, Nilton de Aquino. Contabilidade pública na gestão municipal. São Paulo: Atlas, 2017.

BRASIL. Constituição da República Federativa do Brasil de 1998. Disponível em http://www.planalto.gov.br/ccivil_03/constituicao/constituicao.htm. Acesso em 4 abr. 2019.

BRASIL. Decreto n. 7.185, de 27 de maio de 2010. Dispõe sobre o padrão do sistema integrado de administração financeira e controle, no âmbito de cada ente da federação. Disponível em http://www.planalto.gov.br/ccivil_03/_ato20072010/2010/decreto/d7185.htm. Acesso em 25 maio 2019.

BRASIL. Lei complementar $n$. 101, de 4 de maio de 2000. Estabelece normas de finanças públicas voltadas para a responsabilidade na gestão fiscal e dá outras providencias. Disponível em http://www.planalto.gov.br/ccivil_03/leis/lcp/lcp101.htm. Acesso em 21 abr. 2019. 
BRASIL. Lei complementar n. 131, de 27 de maio de 2009. Acrescenta dispositivos à lei complementar n. 101, de 4 de maio de 2000 . Disponível em http://www.planalto.gov.br/ccivil_03/leis/lcp/lcp131.htm. Acesso em 10 maio 2019.

BRASIL. Lei n. 4.320 de 17 de março de 1964. Estatui normas gerais de direito financeiro para elaboração e controle dos orçamentos e balanços da União, dos Estados, dos Municípios e do Distrito Federal. Disponível em http://www.planalto.gov.br/ccivil_03/leis/14320.htm. Acesso em 5 maio 2019.

BRASIL. Lei n. 8.069, de 13 de julho de 1990. Dispõe sobre o Estatuto da Criança e do Adolescente e dá outras providências. Disponível em http://www.planalto.gov.br/ccivil_03/leis//8069.htm. Acesso em 22 maio 2019.

BRASIL. Lei n. 9.394, de 20 de dezembro de 1996. Estabelece as diretrizes e bases da educação nacional. Disponível em http://www.planalto.gov.br/ccivil_03/leis/l9394.htm. Acesso em 4 de abr. 2019.

BRASIL. Lei n. 12.527, de 18 de novembro de 2011. Regula o acesso a informação previsto no inciso XXXIII do art. 5o, no inciso II do $\S 30$ do art. 37 e no $\S 20$ do art. 216 da CF; altera a lei n. 8.112, de 11 de dezembro de 1990; revoga a lei n. 11.111 de maio de 2005, e dispositivos da lei n. 8.159, de 8 de janeiro de 1991; e dá outras providências. Disponível em http://www.planalto.gov.br/ccivil_03/_ato2011-2014/2011/lei//12527.htm. Acesso em 13 de maio de 2019.

CASTRO, Domingos Poubel de. Auditoria, contabilidade e controle interno no setor público. São Paulo: Atlas, 2018.

DIAS, Reinaldo. Gestão pública: aspectos atuais e perspectivas para atualização. São Paulo: Atlas, 2017.

DOU. Portaria n. 144, de 2 de maio de 2019. Disponível em http://download.inep.gov.br/educacao_basica/saeb/2019/legislacao/portaria_n366_290420 19.pdf. Acesso em 28 set. 2019.

FACHIN, Odília. Fundamentos de metodologia. São Paulo: Saraiva, 2017.

FEE. Disponível em https://www.fee.rs.gov.br/perfilsocioeconomico/coredes/detalhe/?corede=Serra. Acesso em 21 abr. 2019.

FNDE. Disponível em http://www.fnde.gov.br/financiamento/fundeb/perguntas-frequentesfundeb Acesso em 14 abr. 2019.

GIL, Antônio Carlos. Como elaborar projetos de pesquisa. São Paulo: Atlas, 2018.

IBGE. Disponível em https://www.ibge.gov.br/cidades-e-estados/rs/.html?. Acesso em 10 ago. 2019.

INEP. Disponível em http://portal.inep.gov.br/web/guest/educacao-basica/saeb Acesso em 30 set. 2019.

KOHAMA, Heilio. Contabilidade pública: teoria e prática. São Paulo: Atlas, 2016.

LIMA, Diana Vaz de. Orçamento, contabilidade e gestão no setor público. São Paulo: Atlas, 2018.

LIMA, Severino Cesário de; MUNIZ, Josedilton Alves. Contabilidade pública: análise financeira governamental. São Paulo: Atlas, 2016.

MATIAS-PEREIRA, José. A governança corporativa aplicada no setor público brasileiro. Administração Pública e Gestão Social, Viçosa, v. 2, n. 1, 2010, p. 109-134. 
MATIAS-PEREIRA, José. Manual de metodologia da pesquisa científica. São Paulo: Atlas, 2019.

MCASP. Manual de contabilidade aplicada ao setor público. Disponível em http://www.tesouro.fazenda.gov.br/-/mcasp. Acesso em 1ํ maio 2019.

MEC. Disponível em http://portal.mec.gov.br/conheca-o-ideb. Acesso em 30 set. 2019.

NBC TSP EC de 23 de setembro de 2016. Estrutura conceitual para elaboração e divulgação de informações contábil geral pelas entidades do setor público. Disponível em http://www.fazenda.mg.gov.br/governo/contadoria_geral/legislacao/tipolegis//nbctspec.pdf. Acesso em 25 abr. 2019.

PORTAL DA TRANSPARÊNCIA. Orçamento público. Disponível em http://www.portaltransparencia.gov.br/entenda-a-gestao-publica/orcamento-publico. Acesso em 1ำ maio 2019.

TCE/RS. Disponível em http://www1.tce.rs.gov.br/portal/page/portal/tcers/inicial. Acesso em 30 maio 2019.

UOL Educação. Investimento em educação: evolução. Disponível em https://educacao.uol.com.br/noticias/2019/05/02/em-4-anos-brasil-reduz-investimento-emeducacao-em-56.htm. Acesso em 31 ago. 2019.

Alex Eckert é professor na Universidade de Caxias do Sul.

Orcid: http://orcid.org/0000-0002-8704-9549.

Endereço: Rua Francisco Getúlio Vargas, 1130 - 95070-560 - Caxias do Sul - RS Brasil.

E-mail: alex.eckert@bol.com.br.

Deise Cioato é profissional da área de Contabilidade.

Orcid: http://orcid.org/0000-0001-9504-4353.

Endereço: Rua Francisco Getúlio Vargas, 1130 - 95070-560 - Caxias do Sul - RS Brasil.

E-mail: dcioato@ucs.br.

Marlei Salete Mecca é professora na Universidade de Caxias do Sul.

Orcid: http://orcid.org/0000-0001-7545-3184.

Endereço: Rua Francisco Getúlio Vargas, 1130 - 95070-560 - Caxias do Sul - RS Brasil.

E-mail: msmecca@ucs.br.

Recebido em 12 de fevereiro de 2020.

Aceito em 20 de abril de 2020.

(c) (i) 